\title{
English Possessive 's: Clitic and Affix
}

\author{
John J. Lowe
}

University of Oxford

\section{Introduction}

The synchronic syntactic analysis of the Present-Day English (PDE) possessive 's has been the subject of considerable debate; most recently Börjars et al. (2012) with earlier references. Some scholars, e.g. Zwicky (1987), Lapointe (1990), Miller (1991), Payne (2009), seek to analyse the English possessive as an 'edge affix', i.e. an affix attached not to words but to syntactic phrases. Others, e.g. Quirk et al. (1985), Anderson (2008), seek to avoid positing such a category and analyse possessive 's rather as a clitic. Little progress seems to be made, however, in determining which analysis is preferable; rather both contrasting viewpoints continue to be widely advocated by different scholars.

Essentially, these two opposing views continue to exist in contention because there is good evidence in favour of both. The majority of possessives actually occurring in speech, i.e. simple possessives in which the possessor noun directly precedes the possessum, are technically ambiguous. That is, we could analyse the possessive marker in sentences like (1) either as a clitic, or as an affix (a genitive case morpheme) on the possessor noun.

\section{(1) Henry's cars.}

Clear evidence for the affixal analysis comes from lexically irregular possessive forms. Some nouns ending in a sibilant show a 'zero' possessive form (in contrast to the expected / Iz/ allomorph of 's); this is found with all regular plurals (2a), but not all irregular plurals ending in sibilants (2b, but contrast $2 \mathrm{c}$ which could be singular or plural). Some singular nouns are also affected (2c), and proper names can show variation $(2 \mathrm{~d}-\mathrm{e})$.
a. The ducks' $(/ \mathrm{d} \Lambda \mathrm{ks} /)$ pond. ${ }^{*}$ The ducks's $(/ \mathrm{d} \Lambda \mathrm{ksiz} /)$ pond.
b. The geese's (/girsiz/) shed. *The geese' (/girs/) shed.

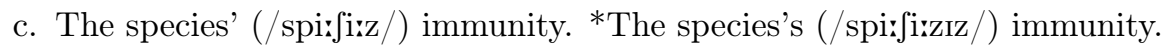
d. Rameses' (/ræməsizz/) statue. *Rameses's (/ræməsizzız/) statue.
e. James' (/dzermz/) book. James's (/dzermzız/) book.

On the other hand, phrasal possessives provide strong evidence for the clitic analysis. When the possessor noun is not the final word in the possessor phrase, possessive 's appears not after the head possessor N, but after the final word of the possessor phrase, regardless of the grammatical category or syntactic status of the word in question. The distribution of the possessive 's in this construction is just what we would expect of a clitic: it is entirely unselective. To maintain a fully affixal analysis in a broadly lexicalist framework we would be forced to posit that every word in the lexicon, noun, verb, adjective, adverb, preposition etc. has an inflectional possessive or 'genitive' form; such a suggestion is clearly unsatisfactory.

$$
\text { a. The Queen of England's hat. }
$$$$
\text { c. The boy opposite me's sister. }
$$

b. Someone I know's brother.

d. The man I live with's girlfriend.

There is, of course, more evidence of various sorts for both the clitic and affixal analyses; though I have no space here to treat these things, none is incompatible with the analysis presented below.

\section{Diachrony}

Although the diachronic origins of the PDE possessive have no necessary consequences for its synchronic analysis, when we consider the Late Middle English and Early Modern English evidence we find important parallels for the PDE situation. Again much has been written on the origins of the PDE possessive, as it represents one of the best examples of the theoretically problematic phenomenon of degrammaticalization; see in particular the work of Allen $(1997,2003,2008)$ with earlier references.

The English possessive $-s$ clearly began life as an affix, and was still a genitive case morpheme in Old English, existing alongside a variety of genitive case allomorphs distributed according to declensional class. Gradually, the -s morpheme spread at the expense of other morphemes. As shown by Allen (2003), in the later Middle English period (1300-1500 A.D.) there is evidence for both an affixal and clitic possessive 
construction existing side by side. Morphologically 'irregular' (i.e. lexically specific) genitive forms are still found, but all or nearly all nouns have the option of using - (e)s. At the same time the phrasal genitive became fully established as a possibility (though it remained rare). What many (including Allen) assume was a reanalysis of affix as clitic must have occurred gradually over a long period of time; between the $14^{\text {th }}$ century and the early $17^{\text {th }}$ century both phrasal (i.e. clitic) and combined (i.e. affixal) possessives exist side by side.

Even more tellingly, the phrasal possessive originated in certain syntactic contexts, and later spread, as discussed by Rosenbach (2004). It originated in contexts where the possessor 'phrase' was most easily analyzable as a single syntactic unit, namely with appositional phrases, coordinated phrases and fixed, lexicalized expressions (esp. of the type [TITLE of PLACE]'s X). It is clear, then, that we cannot talk about an absolute change from affix to clitic, but must acknowledge a gradual process of change over time.

Assuming, therefore, that the existence of the phrasal possessive is sufficient to admit a clitic $-s$, there was a stage in early Middle English where the possessive existed both as a clitic and as an affix. That is, there was a time when the phrasal (clitic) possessive could be used in certain syntactic contexts, while in other contexts the non-phrasal (affixal) form was required. If this was possible in Middle English, it stands to reason that the same is at least possible in PDE.

\section{LFG and 'Lexical Sharing'}

Treating the PDE possessive as both clitic and affix could be considered theoretically undesirable. If the possessive is both clitic and affix, not only is it less clear how a coherent, unified analysis could be undertaken, but there are also practical problems, such as how to prevent a clitic from appearing when the affix appears, or vice versa.

By utilizing Lexical-Functional Grammar (LFG; Bresnan, 2001; Dalrymple, 2001; Falk, 2001), and in particular the theory of 'Lexical Sharing' developed by Michael Wescoat $(2002,2005,2007,2009)$ in this framework, both the theoretical and technical problems of treating the possessive as both clitic and affix can be overcome. In the following I adapt Wescoat's Lexical Sharing model in various ways to fit more mainstream LFG architectural assumptions; space does not permit me to explain these adaptions in any detail, but the fundamentals of Wescoat's approach are preserved.

LFG assumes a separate level of grammatical representation besides the hierarchical constituent structure (and besides the functional structure), the s-string (Kaplan, 1987), which essentially represents a sequence of words as a string, i.e. a set of syntactic elements linearly ordered in accordance with their 'surface' order. The constituent structure is then projected from the s-string, in formal terms by means of a projection $\pi$. Usually, one item in the s-string maps to one item in the c-structure. Wescoat shows, however, that certain sets of words in some languages are best analysed by assuming that one item in the s-string (Wescoat's 'l-structure') corresponds rather to two nodes in the c-structure. This is the case, for example, with pronoun-auxiliary contractions in PDE, and preposition-determiner contractions in French and German. By permitting a one-to-two correspondence, a consistent hierarchical representation can be obtained, for example, for all French prepositional phrases, despite the fact that in some of these phrases the preposition and following determiner are clearly separate words (e.g. ̀̀ $l a)$, while in others they are clearly a single lexical item (e.g. $a u, d u)$.

(4)

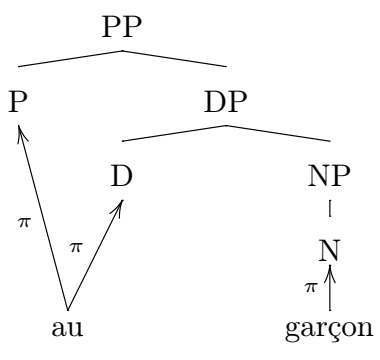

to.the
(5)

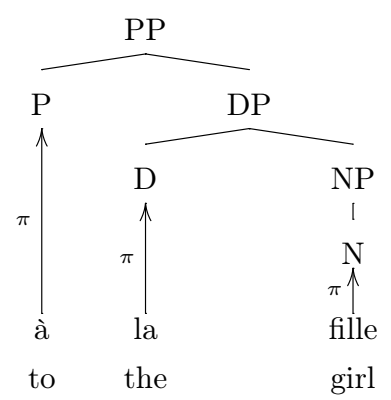

\section{The Lexically Shared Possessive}

We now have three possibilities for the PDE possessive, in relation to which the regular possessive formation (1) is in principle ambiguous: 
(6) Clitic:

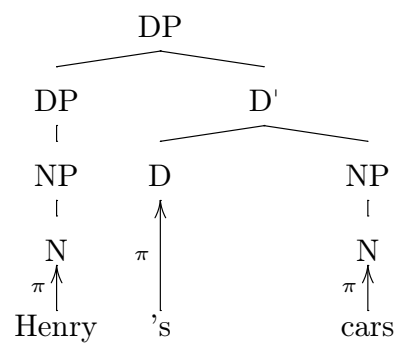

(7) LS affix:

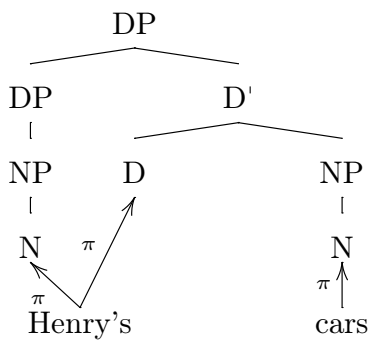

(8) Affix:

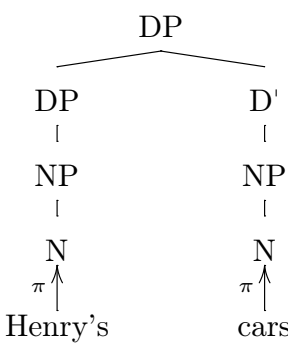

We have seen that some contexts provide clear support for a clitic possessive, while others provide good support for an affix, such that we can assume that both formations exist side by side in PDE. A phrasal possessive such as $(3 \mathrm{~b})$ requires the clitic analysis (9), since otherwise we would have to assume that every finite verb form (etc.) has an affixal 'possessive' form used only in these contexts. Since the phrasal possessive requires a clitic, it is most parsimonious to assume the clitic construction also for all regular possessives, i.e. (6) in preference to (7) or (8). In contrast, nouns with the affixal 'zero' possessive (2c) utilize Lexical Sharing (10) such that, while these possessive forms are single lexical items (since the possessive marker is an affix), their syntactic parallelism with the two word (noun plus possessive clitic) sequences is preserved, yielding a consistent syntactic analysis of PDE possession.

(9) Someone I know's brother.

DP

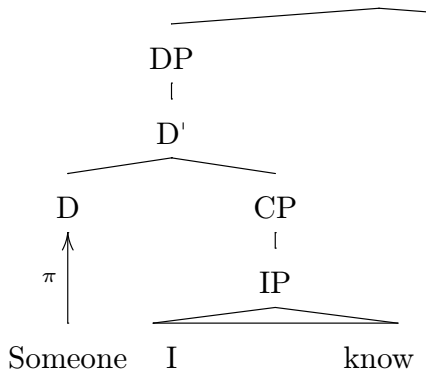

(10) The species' immunity.

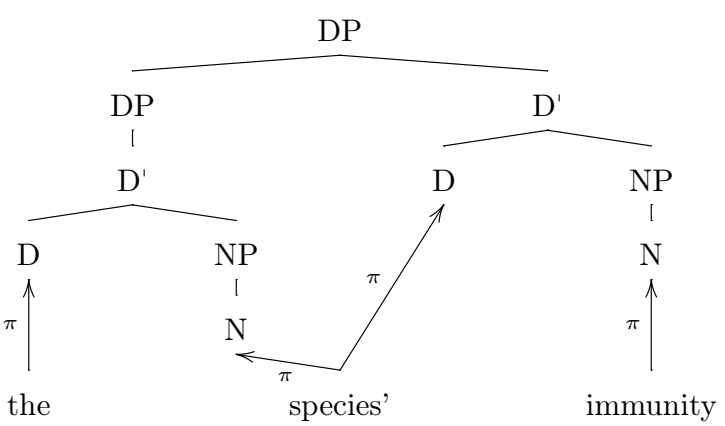

Similarly, when the last word of a phrasal possessive is a noun that takes an affixal 'zero' possessive, lexical sharing is utilized in precisely the same way (11).

(11) The female of the species' deadliness.

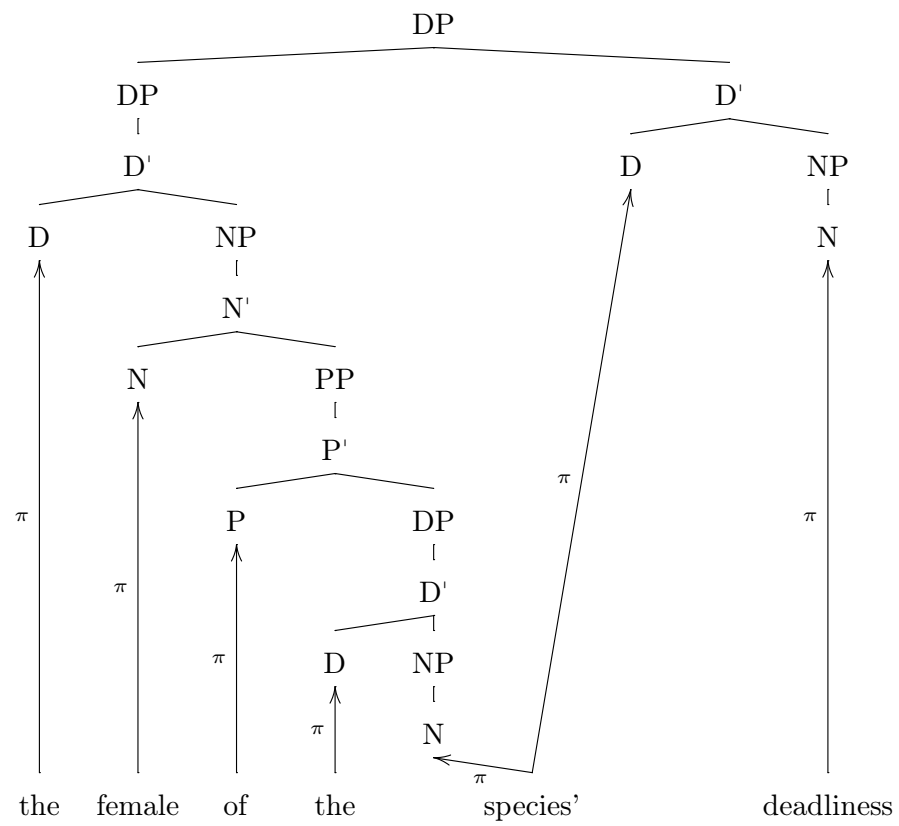


In (11) the linear sequence of noun species followed by possessive D surfaces as the lexically idiosyncratic possessive form of the noun, species', even though species itself is not the possessor noun and has no direct syntactic relation with the possessive D node. We can assume that the 'possessive' form of the noun, species', is listed in the lexicon. However, this form is not used when the noun is itself the possessor, but rather when the noun appears at the end of a possessor DP, directly preceding, in linear terms, the head $\mathrm{D}$ node, i.e. when the 'next' node in linear terms is the $\mathrm{D}^{0}$ node of the superordinate DP. This can be specified along the lines of Wescoat's lexical instantiation rules, which in our terms can be included in the lexical entry in the following way.

(12)

$$
\begin{array}{|l|}
\hline \text { species': } \\
*_{\pi}=\mathrm{N} \mathrm{D} \\
\mathrm{N}(\downarrow \mathrm{PRED})=\text { 'species' } \\
\mathrm{D} \uparrow \mathrm{POSS} \\
\hline
\end{array}
$$

The partial lexical entry in (12) states that the word species' maps to a sequence of $\mathrm{N}$ followed by $\mathrm{D}$ in c-structure, the meaning of the $\mathrm{N}$ is 'species', and the $\mathrm{D}$ must have a possessor at f-structure. This is sufficient to ensure that lexically specified possessives like species' are used only when final in the possessor DP (whether the head of that DP or not).

So the PDE possessive exists in both clitic (6) and LS affix (7) forms, but there is no evidence for a 'simple' affixal (8) possessive. Space does not permit further discussion, but it is possible to treat all the data, much of which has not been mentioned here, in this model.

\section{Conclusion}

Linguistic categorization is rarely neat, insofar as linguistic phenomena rarely fit absolutely into the boxes we construct for them. While there is something theoretically elegant about being able to say that the PDE possessive is purely a clitic, or purely an affix, the evidence does not support either absolute analysis. I have, I hope, shown that it is in fact possible to provide a coherent, consistent and unified analysis of the PDE possessive, while at the same time recognizing that it displays properties of, and to an extent is, both clitic and affix. The Lexical Sharing LFG analysis utilized here permits a more fine-grained representation of such dual-nature categories, making the analysis closer, perhaps, to the reality of non-discrete linguistic phenomena.

\section{References}

Allen, Cynthia L. (1997). 'The Origins of the 'Group Genitive' in English'. Transactions of the Philological Society 95(1), pp. 111-131. - Allen, Cynthia L. (2003). 'Deflexion and the development of the genitive in English'. English Language and Linguistics 7(1), pp. 1-28. • Allen, Cynthia L. (2008). Genitives in Early English: Typology and Evidence. Oxford University Press. • Anderson, Stephen R. (2008). 'The English "Group Genitive" is a Special Clitic'. English Linguistics 25, pp. 1-20. • BörJars, Kersti, David Denison, and Alan ScOTT (eds.) (2012). Morphosyntactic Categories and the Expression of Possession. Benjamins. • BRESNAN, JoAN (2001). Lexical-Functional Syntax. Blackwell Publishing. • DAlRymple, MARY (2001). Lexical Functional Grammar. Academic Press. • FAlK, Yehuda N. (2001). Lexical-Functional Grammar : an Introduction to Parallel Constraint-Based Syntax. CSLI Publications. • KAPlan, Ronald M. (1987). 'Three Seductions of Computational Psycholinguistics'. In Whitelock et al. (eds.), Linguistic Theory and Computer Applications, Academic Press, pp. 149-181. • Lapointe, Steven G. (1990). 'Edge features in GPSG'. In Ziolkowski et al. (eds.), Papers from the $26^{\text {th }}$ Regional Meeting of the Chicago Linguistic Society, vol. 1: The Main Session, Chicago Linguistic Society, pp. 221-235. • Miller, PhiliP H. (1991). Clitics and constituents in phrase-structure grammar. Ph.D. thesis, Rijksuniversiteit te Utrecht. • PAYne, John (2009). 'The English genitive and double case'. Transactions of the Philological Society 107(3), pp. 322-357. - Quirk, Randolf, Sidney Greenbaum, Geoffrey Leech, and Jan Svartvik (1985). A Comprehensive Grammar of the English Language. Longman. • RosenBACH, AnETTE (2004). 'The English s-genitive: A case of degrammaticalization?' In Fischer et al. (eds.), Up and Down the Cline: The Nature of Grammaticalization, Benjamins, pp. 73-96. • Wescoat, Michael Thomas (2002). 'On Lexical Sharing'. Ph.D. Thesis, Stanford University. • Wescoat, Michael Thomas (2005). 'English Nonsyllabic Auxiliary Contractions: An Analysis in LFG with Lexical Sharing'. In Online Proceedings of the LFG05 Conference, CSLI Publications, pp. 468-486. • Wescont, Michael Thomas (2007). 'Preposition-Determiner Contractions: An Analysis in Optimality-Theoretic Lexical-Functional Grammar with Lexical Sharing'. In Online Proceedings of the LFG07 Conference, CSLI Publications, pp. 439-459. • Wescoat, Michael Thomas (2009). 'Udi Person Markers and Lexical Integrity'. In Online Proceedings of the LFG09 Conference, CSLI Publications, pp. 604-622. - Zwicky, ARnold M. (1987). 'Suppressing the Zs'. Journal of Linguistics 23, pp. 133-148. 